\title{
THE IMPROVEMENT OF GEOTECHNICAL SUBSURFACE MODELS THROUGH THE APPLICATION OF S-WAVE REFLECTION SEISMIC EXPLORATION
}

\author{
Jan Brouwer, Ranajit Ghose, Klaus Felbig, and Vincent Nijhof \\ OYO-CAG, Archimedesbaan 16 Nieuwegein, The Netherlands
}

\section{INTRODUCTION}

Due to its relatively high sensitivity to the distribution of elastic parameters, the seismic technique is quite suitable for geotechnical subsurface investigations. However, practical implementation of the P-wave exploration technique for soft-soil and shallow-groundwater conditions, as often encountered in the Netherlands, may often prove problematic; the highimpedance contrast at the groundwater table may induce strong reverberations and guided waves, resulting in a distortion of the seismic record at shallow depth. The use of buried sources may be of some advantage, but at the cost of a considerable decrease in the speed of operation.

Since shear waves are rather insensitive to the water content of the soil, shear-wave exploration may sometimes be successfully applied under conditions where $P$ waves fail to yield acceptable results. Furthermore, as shear waves address the rigidity of the soil more directly than $P$ waves, the application of shear-wave techniques in geotechnical investigations appears attractive.

Effective application of a seismic method requires that both the quality of the data and the speed of acquisition are acceptable. Traditional S-wave sources are often too heavy to be easily and speedily handled and typically show too limited a frequency content to yield sufficient detail in the resulting subsurface models.

In this paper we present a recently developed horizontal vibrator that is characterized by its high portability, source strength, and resolving power. Furthermore, we present a number of field examples in which we show the strength of the horizontal vibrator in high-resolution shear-wave seismic exploration.

\section{HORIZONTAL VIBRATOR}

As opposed to the strength of sources used in shallow P-wave exploration (e.g., weightdrop, hammer, and Buffalo gun), the strength of an S-wave source of comparable dimensions is quite limited. As an example, a weight of $25 \mathrm{~kg}$, dropped from a height of $3 \mathrm{~m}$ will yield a peak force that may easily be as high as $100 \mathrm{kN}$. A traditional wooden sledgehammer source of $25 \mathrm{~kg}$ will start to slip at forces that may be much lower than $250 \mathrm{~N}$ and consequently loose much of its efficacy. The generation of a higher force with such an impact shear-wave source requires loading of the plank with a mass that may easily exceed $10,000 \mathrm{~kg}$. 


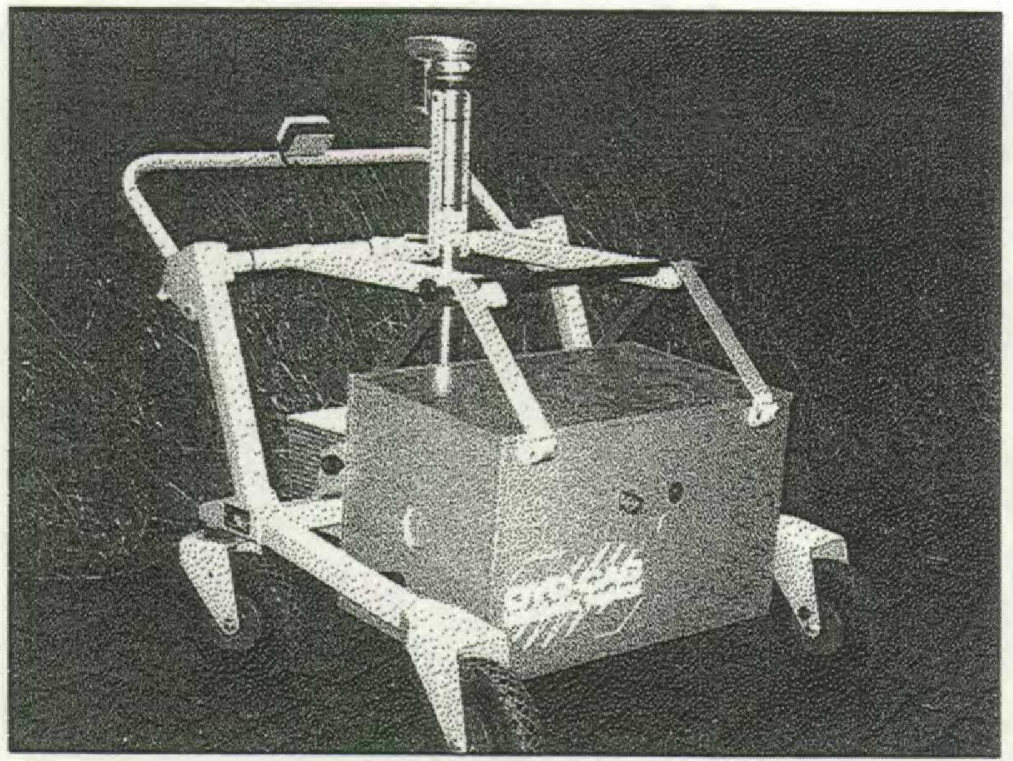

SOURCE CHARACTERISTICS

Shaker

Baseplate mass $\quad 29 \mathrm{~kg}$

Reaction mass $\quad 72 \mathrm{~kg}$

Holddown mass (optional) $68 \mathrm{~kg}$

Force

$500 \mathrm{~N}$

Max. Output Power $\quad 1 \mathrm{~kW}$

Bandwidth

$5-500 \mathrm{~Hz}$

Amplifier

Power Consumption $\quad 4 \mathrm{~kW}$

Max. Output Current 17 Amps

Max. Output Voltage $\quad 70 \mathrm{~V}$

Control

PC-based generation of linear and non-linear sweeps and arbitrary signals.

Figure 1. The horizontal vibrator in its field carriage.

Since for vibratory sources the effective source strength is determined by both force output and sweep duration, such a source offers low weight and acceptable source strength; for an $8 \mathrm{~s}$ sweep the effective source strength of OYO's newly developed horizontal vibrator (figure 1) is comparable to that of a sledge-hammer source 50 times its weight whereas the vibrator shows a significantly broader frequency band. For typical Dutch conditions this portable horizontal vibrator provides a characteristic wavelength of less than a meter and an observed resolution for the top 25 meter in the decimeter scale; a resolution that is comparable to that obtained in downhole geotechnical investigations.

\section{FIELD EXAMPLE 1: NIEUWEGEIN}

S-wave reflection seismic measurements were carried out together with Cone Penetrometer Tests (CPT) and a Vertical Seismic Profile (VSP). Seismic data were acquired by an array of 30 horizontal geophones, planted at $.5 \mathrm{~m}$ spacing. The vibrator sweep range was $50-600 \mathrm{~Hz}$, sweep duration was $3.5 \mathrm{~s}$, and the vertical stack was 4 -fold.

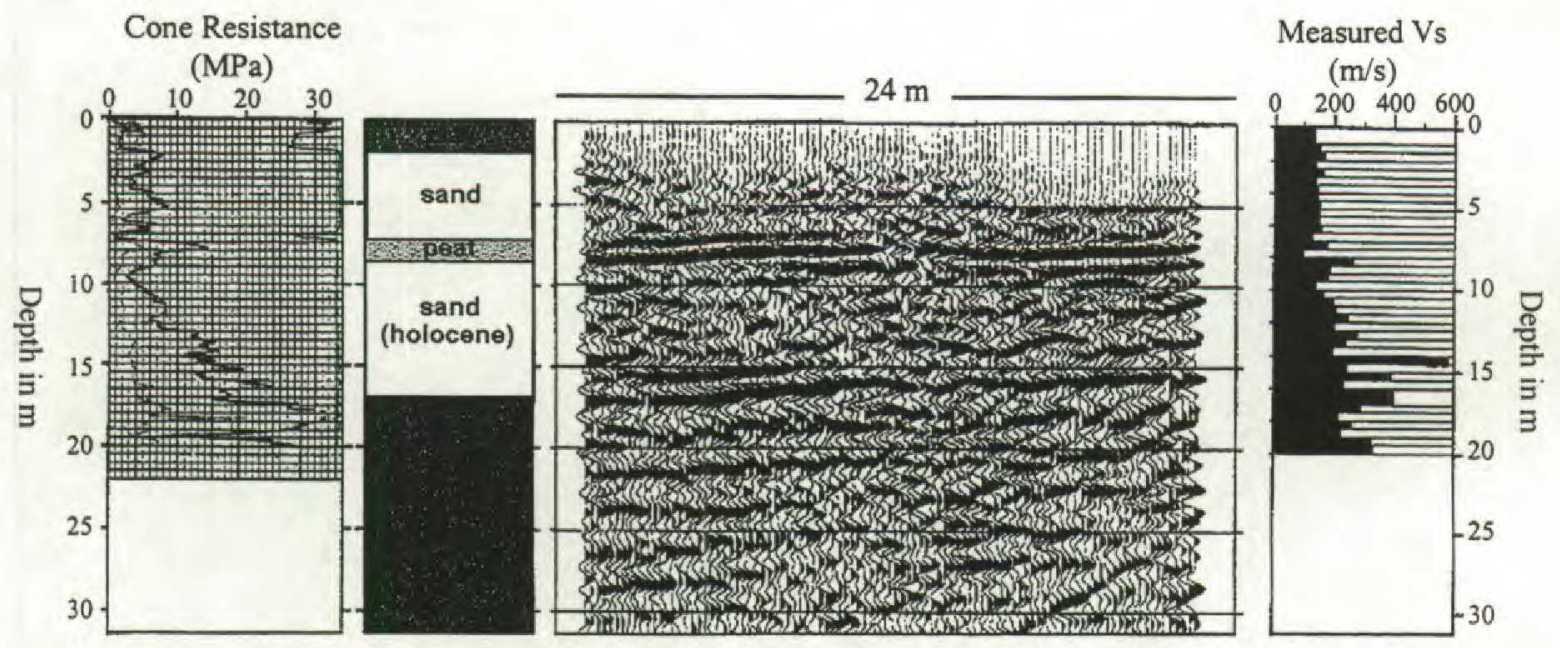

Figure 2. From left-to-right: CPT, Lithology, Reflection Profile and interval velocity from VSP.

At 7-8 $\mathrm{m}$ and 16-17 $\mathrm{m}$ two clear events can be recognized in the seismic profile in figure 2 . They correspond respectively to a thin peat layer and the Holocene-to-Pleistocene sand 
boundary. In addition to these two events many intrabed reflections are observed which map sand lenses of varying stiffness. A good correlation is observed between the shear stiffness determined by CPT and the interval velocity derived from the VSP. The stacking velocity was therefore converted to an interval velocity model and subsequently translated into dynamic shear modulus (figure 3 ).
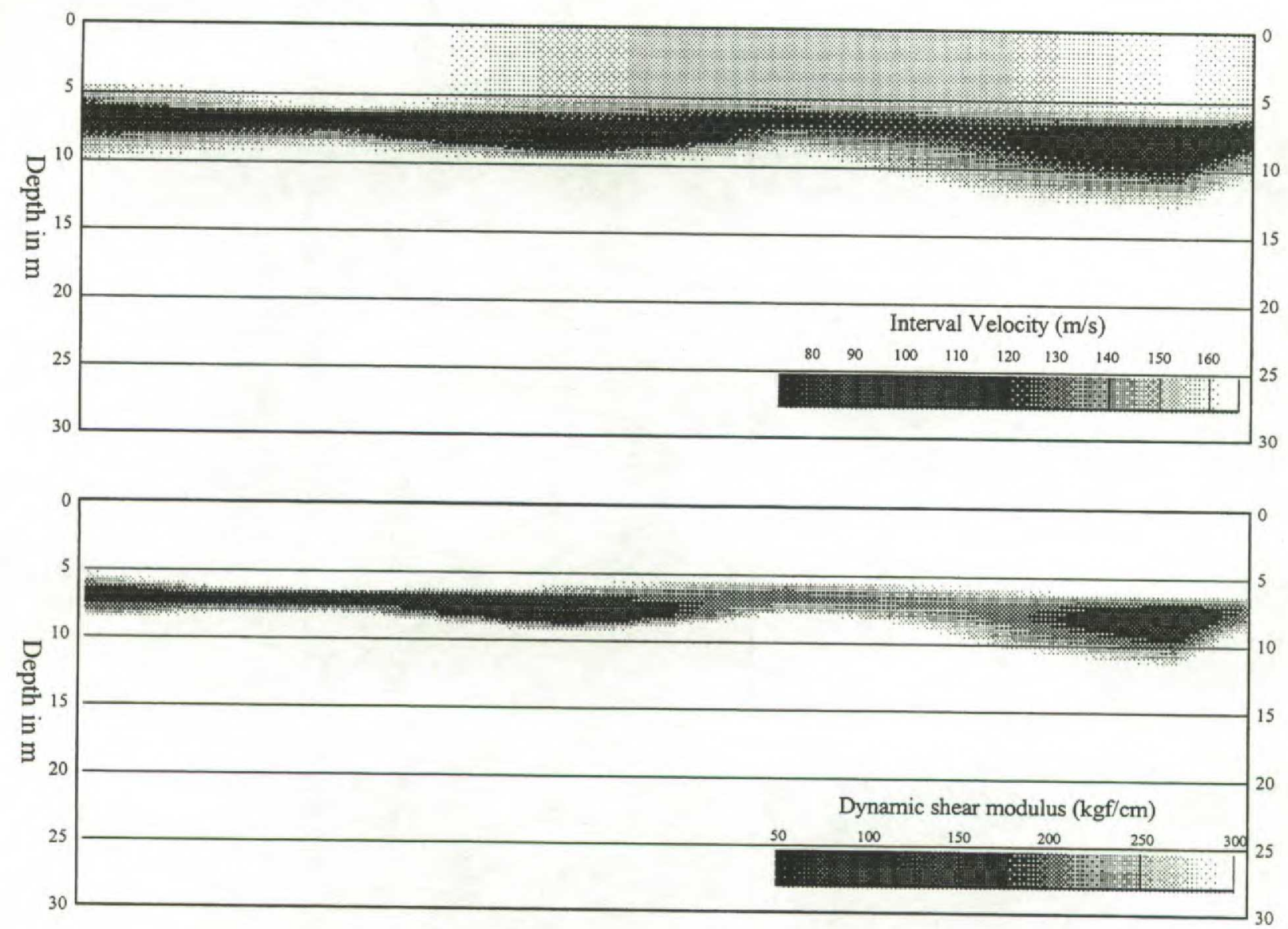

Figure 3. Interval velocity as derived from the stacking velocity model (top) and the dynamic shear modulus (bottom).

\section{FIELD EXAMPLE 2: ROTTERDAM}

A reflection seismic survey was conducted to explore the planned route of a fresh-water supply pipe of $\sim 2 \mathrm{~m}$ diameter and locate obstacles. Main attention was focused on the top 25 $\mathrm{m}$ (Holocene). A 48-channel spread of single horizontal geophones was used at $.5 \mathrm{~m}$ geophone interval and $2 \mathrm{~m}$ source interval. The vibrator sweep range was $20-250 \mathrm{~Hz}$, sweep duration was $7.5 \mathrm{~s}$, and the vertical stack was 8 -fold. Sources and receivers were placed perpendicular to the spread direction, thus recording mainly SH- and Love wave. The rate of progress under the prevailing field conditions was approximately $250 \mathrm{~m} / \mathrm{day}$.

The depth section displayed in figure 4 exhibits a resolution in the top $10 \mathrm{~m}$ of less than $.5 \mathrm{~m}$ and shows a remarkably good correlation with the CPT results displayed as overlays.

\section{ACKNOWLEDGEMENTS}

The authors wish to acknowledge Gemeentewerken Rotterdam and Gemeentelijk Havenbedrijf Rotterdam for granting permission to publish the results obtained in the Hartelkanaal survey. 


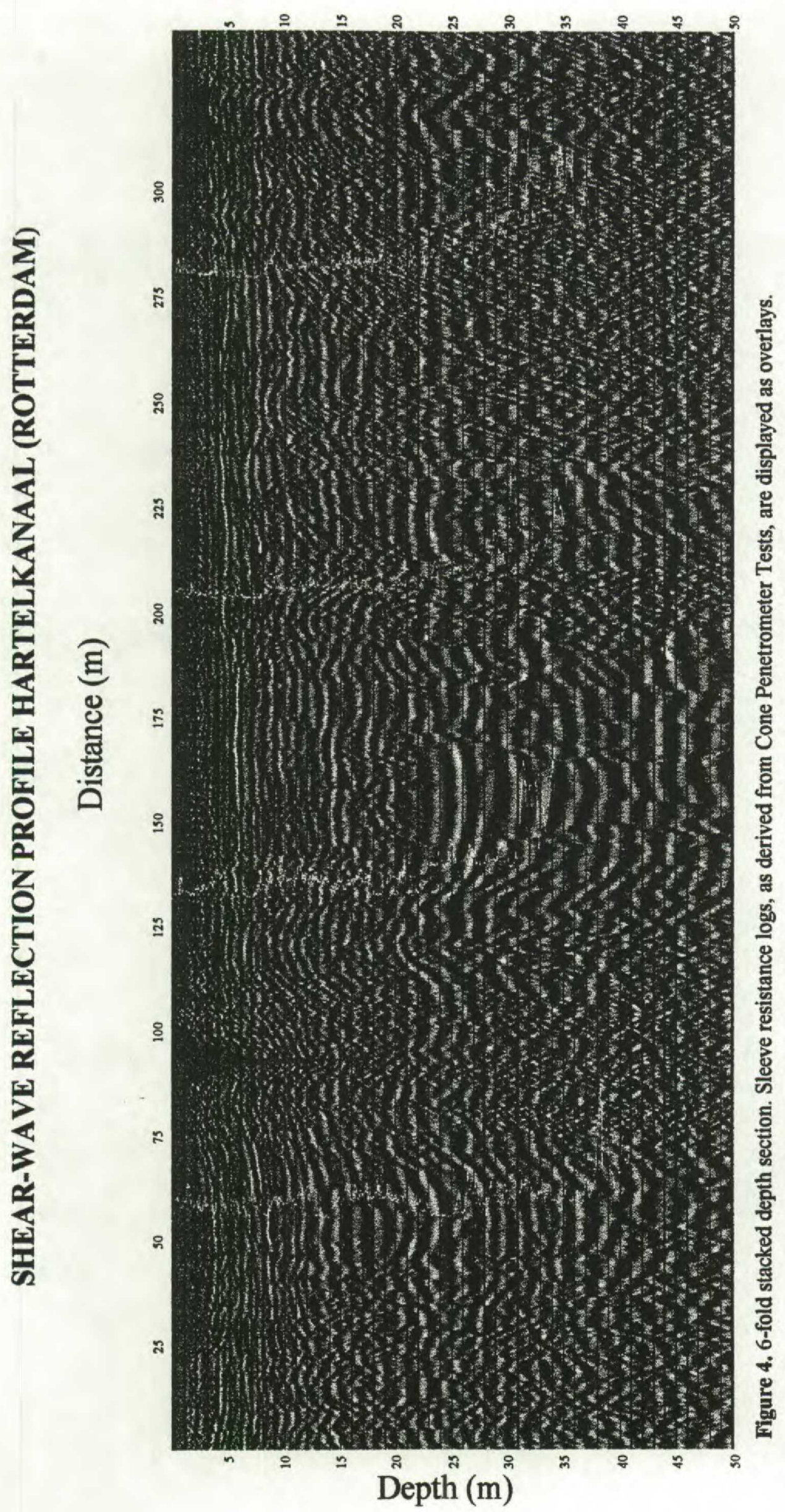

